\title{
Kilis Kentsel Sit Alanında Kullanıcı Odaklı Mekânsal Algı Belirlemeleri
}

\section{User Focused Spatial Perception Determinations at Kilis Urban Conservation Areas Saliha TAŞÇıoĞLUa M.Faruk ALTUNKASA}

a Öğr. Gör. Kilis 7 Aralık Üniversitesi, Kilis Meslek Yüksek Okulu, Park ve Bahçe Bitkileri Bölümü, Kilis, 79000, Türkiye bProf. Dr.Çukurova Üniversitesi, Ziraat Fakültesi, Peyzaj Mimarlığı Bölümü, Adana, 01000,Türkiye,

Article history: Received 21-11-2017/ Accepted 23-07-2018

\section{ÖZET ABSTRACT}

\begin{abstract}
Algı insanların duyular yoluyla çevreden edindiği izlenimleri bilgiye dönüştürmesidir. Mekân ise insanlar tarafından inşa edilmiş bir çevrenin temelini oluşturmaktadır. Ayrıca kesin sınırlarla tanımlanmamış, geçmiş deneyim ve birikimler doğrultusunda gelișen en önemli unsurdur. Bu izlenimler doğrultusunda kullanıcılar tarafından bir değer ve anlam yüklenen mekânlar daha kolay algılanabilmektedir. Bu açıdan değerlendirildiğinde Mekânsal algılama kavramı duyumla başlayıp algıya ve anlam yüklemeye uzanan bir süreç olarak tanımlanmaktadır. Calışma Kilis Kentsel Sit Alanında yer alan kentsel kimlik öğelerinin mekânsal algılamalarının anket uygulamasıyla ortaya konulmasını amaçlamıştır. Bu bağlamda, katılımcılardan fotoğraflar aracılığıyla belirlenen kentsel kimlik öğelerini belirlemeleri istenmiş ve bu öğelerin algılanma oranları tespit edilmiştir. Kullanıcıya yönelik araştırma ile kentsel kimlik öğelerinin belirlenmesini sağlayan özellikleri tespit etmeye çalışırken, açık uçlu sorular ile de kullanıcıların kent içerisinde belirgin buldukları noktaları belirtmeleri istenmiştir. Çalışma sonunda Meydan öğesinin en yüksek algı oranına sahip kentsel kimlik öğesi olduğu görülmüştür.
\end{abstract}

Perception is the transformation of impressions that people acquire from the environment into wisdom. The place is, on the other hand, the basis of a people-built environment. In addition, it is also the key factor that has not been defined with definite boundaries, but developed in the direction of past experience.In the direction of these impressions, the places which have a value and meaning for users can be perceived more easily. When considered from this perspective, the concept of spatial perception is defined as a process starting from sensation and extending to perception and meaning. The study aims to reveal the spatial perceptions of Urban Identity Items by user research in the Kilis Conservation Areas. In this context, the participants were asked to identify the Urban Identity Items specified through the photographs and their perception rates were evaluated. While trying to identify features that determine the identification of Urban Identity Items with user surveys, users were also asked to identify the significant places in the city with openended questions. At the end of the study, it was observed that the Square element is the most significant Urban identity element with highest perception rate.

Anahtar Kelimeler: Mekânsal Algı, Kentsel Sit Alanları, Mekân

Keywords: Spatial Perception, Urban Conservation Areas, Space

\section{GİRİŞ}

Algı, duyular yoluyla alınan bilginin seçilmesi, düzenlenmesi ve yorumlanması süreci olarak tanımlanmaktadır(Porteous, 1996; Bell,1999; Çakçı ve Çelem, 2009). Bu tanım çevresel psikoloji üzerinde çalışan Downs ve Stea (1973) (Özak ve Gökmen, 2009'dan) tarafından bilişim ile birlikte ele alınmıştır. Mekânsal çevreden alınan bilgilerin kodlanması, saklanması, hatırlanması ve tekrar kodların çözülmesi, süreci olarak açıklanmaktadır. Bu açıdan bakıldığında algı kavramı duyular yoluyla yakın çevreden edinilen, alınan uyaranların işlenerek bilgiye dönüştürülme sürecine, bir başka deyişle "kavrayışa" ilişkindir. Algılama süreci ise bellekte depolanmış, edinilmiş bilgiler ve duyumsanan fiziksel veriler ile gerçekleşmektedir. Algılanan bir durumun, mekânın anlamlandırılabilmesi için; bireyin geçmiş deneyimleri, eğitim, kültür öğeleri, ışık, ses, koku, doku gibi çevresel etkenler ya da herhangi içsel neden söz konusu olabilir (Turgay,2013). Başka bir deyişle algı çevresel uyarı ve bilgileri süreçlendirme olgusudur. Bu tepki düzeneği aşağıdaki gibi açıklanabilir:

1. Çevrelenen organizmanın çevresinden gelen uyarı organizma tarafından algılanır. En dar anlamında algı bir uyarı aracılığıyla varlıktan duyular yoluyla bilgi sahibi olmaktır.

2. Algılanan şey, beyne iletilir. Beyin tarafından algılanmak demek bir nesneyi eski deneyimler yoluyla yorumlamak demektir.

3. Algılanan şey uyumlandırılıp kavrandığında biliş olur, yani organizmanın tanıdığı, bildiği bir şeye dönüşür. 
4. İlk uyarıya bir tepki gösterilirse, bu önceden bilinen bir imgeye gönderme yapılarak gerçekleşmiştir (Stea ve Downs, 1970; Porteous, 1977; Gür, 1996).

Mekân kavramı ise algıların ve düşüncelerin toplamı olmanın ötesinde insanın varoluşunun bir yansımasıdır. Mekân insanlar tarafından inşa edilmiş bir çevrenin temelini oluşturan, kesin sınırlarla tanımlanmamış, geçmiş deneyim ve birikimler doğrultusunda gelişen en önemli unsurdur. Yaşamımızın kabuğunu oluşturan, dış dünya ile ilişkimizi somut anlamda biçimlendiren bir etkiye sahip olan mekân; insan-insan ilişkilerinin ve bu ilişkilerin gerektirdiği donatıların içinde yer aldığı, sınırları olan, örgütlenmenin yapı ve karakterine göre belirlenen tanımlı bir boşluktur (Turgay,2013).

İnsanlar çevreleri boyunca hoşnutluk, heyecan ve rahatlama boyutlarını değerlendirilmektedir (Ward and Russel,1981;Nasar,1990). Bu durumda bireyin içinde yaşadığı çevreyi denetleme biçimi ve düzeyi doyumu sağlamada can alıcı aşamayı oluşturmaktadır. Çevresel biliş sürecine benzer şekilde kentli, kentsel çevreyi denetlemeyi başardığı ölçüde kendini güvenlik içinde hisseder ve o çevrede yaşamaktan dolayı doyum sağlar. Bu da kentle bütünleşme kavramının somutlaşmasına ışık tutar. Bir başka deyişle kentle bütünleşmenin düzeyi kentsel çevreyi denetlemenin tipi ve ölçüsüyle ilgilidir. Kentsel çevreyi denetleyebilmek ise o çevreye ilişkin bilginin düzeyine, içeriğine ve yapısal organizasyonuna bağlıdır (Türksoy, 1996). Çevresel imgeler, gözlemci ve çevresi arasında işleyen iki yönlü bir süreçtir. Çevre, farklılıklar ve ilişkiler ortaya koyar. Gözlemci ise uyum kabiliyeti ve kendi amaçları doğrultusunda gördüklerini seçer, düzenler ve anlamlandırır (Lynch,1960). Çevrenin algılanması, bilinmesi ve değerlendirilmesi, çevrenin duyu organları ile hissedilmesi, çevrenin algılanış biçiminin anlaşılması ve çevrenin niteliklerinin tanınması sonucunda, seçim yapma, karar verme sürecidir (Rapoport, 1977; Önem ve Kılınçaslan, 2005). Bu süreç sonunda çevredeki anlamlar insanlar ve insan amaçları kadar çeşitli ve karmaşık olabilir (Steinitz, 1968).

Çevrenin kendi sahip olduğu formun imgenin oluşturulmasında muazzam bir rol oynadığına şüphe yoktur. Tariflerin açıkça yapılmasında, hatta aynı noktalarda şaşırılmasındaki benzerlikler, edinilen bilgilerin mekâna aşina olmaya dayalı olduğunu gösterir. İmge ile fiziksel form arasındaki bu ilişki mekânsal algımızı oluşturur (Lynch, 1960). Mekânsal algılama kavramı duyumla (ilk imaj ya da imge) başlayıp algıya (genel imaj) ve anlam (gerçek imaj) yüklemeye uzanan bir süreçtir. İçinde yaşadığımız çevre canlılar, nesneler, atomlar, moleküller ve enerjiden oluşmaktadır. Çevredeki fiziksel olaylar ve değişmelerden bizim duyarlı olduğumuz titreşimler, duyu organlarımızda akımlar durumuna geçip beynimize ulaşırlar ve ortam konusunda bilgi sağlamış olurlar. Bu olgu çevredeki varlıkların duyu organlarına yaptıkları etkilerin bütünüdür. Bu etkilerin bilince aktarılması duyumu oluşturur. Diğer bir tanımlama ile duyum insanın dıştan algıladığı bir ortamın ya da mekânın açık bir uyarıcı olmadan bilincine yansıyan ve canlanan biçimidir. Duyum algılama sürecinin fizyolojik bölümünde yer alır (Konaklı vd., 2010).

Kısa ve uzun süreli bellek yapılarının işleyişi mekânın anlamlandırılmasında ve o mekâna ait imgenin oluşmasında önem taşımaktadır. Kişinin geçmiş deneyimleri ile edindiği imgeler, girdiler uzun süreli bellekte saklanmaktadır. Yeni karşılaşılan mekânlarda ilişkilendirme, eşleştirme, karşılaştırma gibi işlemler kullanılarak mekân algılanmakta ve bu mekâna ait imgelem oluşturulmaktadır. Uzun süreli bellekte daha çok kavramsal düşünceler saklandığından dolayı mekânın anlamlı bir bütün olarak algılanmasına imkân sağlanmaktadır (Turgay,2013).

Mekânda kalıcı bellek "Yaşam boyunca mekânla ilgili duyumların, algılamaların, öğrenmenin, deneyimlerin ve anıların yalnızca kendi bileşenleri ile değil; içinde geçen fenomenlerle, ortam özellikleriyle ve yaşamla birlikte, bir başka deyişle "bağlamı" ile birlikte belleğe kaydedilmesi, ilişkilendirilmesi" olarak tanımlanabilir. Kalıcı mekân belleğinin tanımından yola çıkarak kalıcı bellek;

- Mekânın duyum aşaması,

- Mekânın algılanması

- Mekânın belleğe kodlanması olarak üç süreçte oluşmaktadır (Özak ve Gökmen,2009).

Peyzaj algısına yönelik çalışmalar temel olarak peyzaj değerlendirmesinin bir parçasıdır. Peyzaj değerlendirmesi bir peyzajın belirlenen bir takım ölçütleri ne kadar karşıladığını sorgulamaktadır. Peyzaj algısı değerlendirmelerinde ise bu ölçütler genel olarak estetik ya da peyzaj tercihleridir (Parsons and Daniel 2002; Palmer 2003; Çakçı ve Çelem,2009)

Bu çalışma, mekânsal algılamanın, ankete dayalı olarak ölçülebilmesi ve değerlendirilebilmesi amacını taşımaktadır. Mekân ve algı arasındaki ilişkiyi irdeleyen çalışma, bireyin önce 
mekânla ilgili belirleyici noktaları belirlemesi ve ardından mekânı doğru olarak tespit edebilmesi çerçevesinde kurgulanmıştır. Bu ilişkinin derecesini belirlemek amaçlı, anket çalışması ile farklı mekânlar üzerinden sorgulamalar yapılmıştır.

\section{MATERYAL VE YÖNTEM}

Çalışma alanının ana materyalini Kilis Kentsel Sit Alanı oluşturmaktadır (Şekil 1). Alanın belirlenmesinde kentin ilk çekirdek yerleşim bölgesini oluşturması, geleneksel dokuyu koruması, merkezi konumu ve erişilebilir olması etkili olmuştur.

Çalışmada materyal olarak;

- $\quad 1 / 5000$ ölçekli Koruma Amaçlı İmar Planı,

- Uydu Görüntüleri, Fotoğraflar,

- Autocad 2014, Photoshop CS2 programları,

- Anket formları kullanılmıştır.

Çalışmanın aşamalarını şu şekilde ifade etmemiz mümkündür:

\section{1) Alan İçerisinde Yer Alan Kentsel Kimlik Öğelerinin ve Mekânların Belirlenmesi}

Kentsel kimlik ögeleri ve mekânlar; avlu, yapı geneli, yapının karakteristik bölümü, sokak, meydan ve anıt ağaçlar olmak üzere altı grubu içermektedir. Her bir grup için birer örneklem alan seçilmiş ve fotoğraf olarak kullanıcılara sunulmuştur. Seçilen alanların kent içerisindeki dağılımı Şekil 2'de belirtilmiştir.

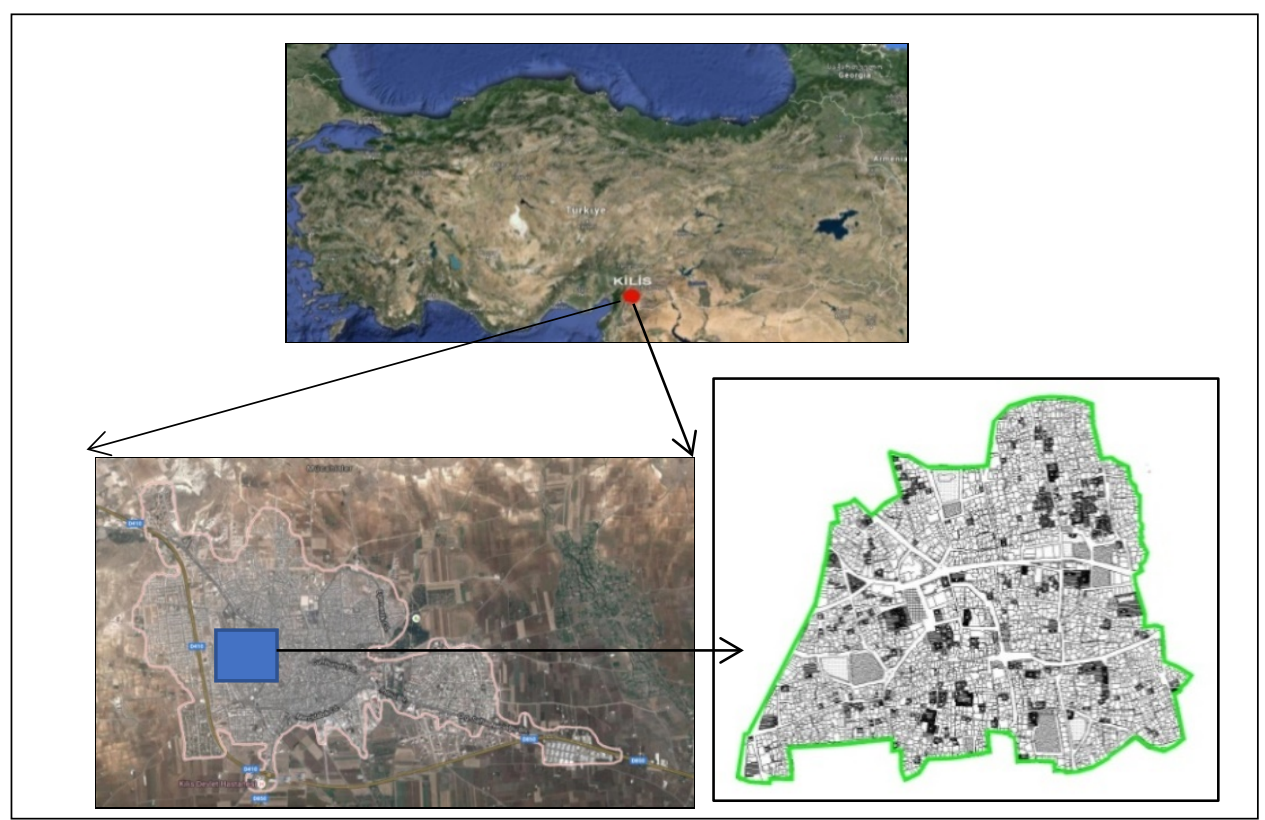

Şekil 1. Çalışma Alanının Coğrafi ve Kentsel Alandaki Konumu

\section{2) Kullanıcı Araştırmasında Anket Formunun Oluşturulması ve Uygulanması}

Anket formları tesadüfi olarak seçilen 100 denek üzerinde uygulanmış ve katılımcıların en az 3 senedir kentte ikamet ediyor olmasına dikkat edilmiştir.

Anket formu iki bölümden oluşmaktadır. İlk bölümde Yaş, Cinsiyet, Eğitim Durumu gibi kullanıcı profiline yönelik sorular yer almakta iken, ikinci bölümde katılımcıların mekânlara ait tespitleri yer almaktadır.

İkinci bölümün İlk aşamasında, Kentsel kimlik öğelerine ait 6 adet fotoğraf kullanıcılara sunulmuştur. Bu aşama algının fizyolojik sürecini içermekte, biçim, renk, ölçü ve doku öğeleri açısından belirleme yapmalarını sağlamaya yöneliktir. İkinci aşamada ise bilişsel süreçte belirleyici olan kullanıcı deneyimi, bilgi birikimi ve kültürel geçmişin katkısı ile bu ögelerin ifade şekli belirlenmeye çalışılmıştır. Bu amaçla katılımcılardan kentte en belirgin buldukları 
mekân ve odakları belirtmeleri istenmiştir. Böylece kent içerisinde kullanıcıların zihinsel haritalarında yer edinen mekânları ifade etmeleri ve bu mekânları kendi içerisinde sıralamaları sağlanmaya çalışılmıştır. Fiziksel ve estetik özelliklerin katkısıyla mekânların algılandığı düşünüldüğünde bu ögelerden hangisinin kullanıcı üzerinde etkisi olduğunu belirleyebilmek için de bir bölüm ayrılarak verilen cevapların nedenleri tartışılmaya çalışılmıştır.

\section{3) Kullanıcı Araştırmasından Elde Edilen Verilerin Sayısal Analizi}

Kullanıcı araştırmasında anket yöntemiyle elde edilen veriler sayısal olarak değerlendirilmiş ve oransal bulgular elde edilmiştir.

\section{4) Görsel Haritaların Oluşturulması}

Bu aşamada kentsel kimlik öğelerinin oranları ve kentin belirgin noktalarının belirlenmesine çalışılmış ve haritalar oluşturulmuştur.

Çalışma katılımcıların, kente ait mekânları ne derece doğru olarak tespit edebildiklerini ölçmek, mekânın tanınmasına yardımcı olan öğeleri belirlemenin yanında, katılımcıların belleklerinde yer alan, kentle ilgili belirgin noktaları saptamak olarak da özetlenebilir.

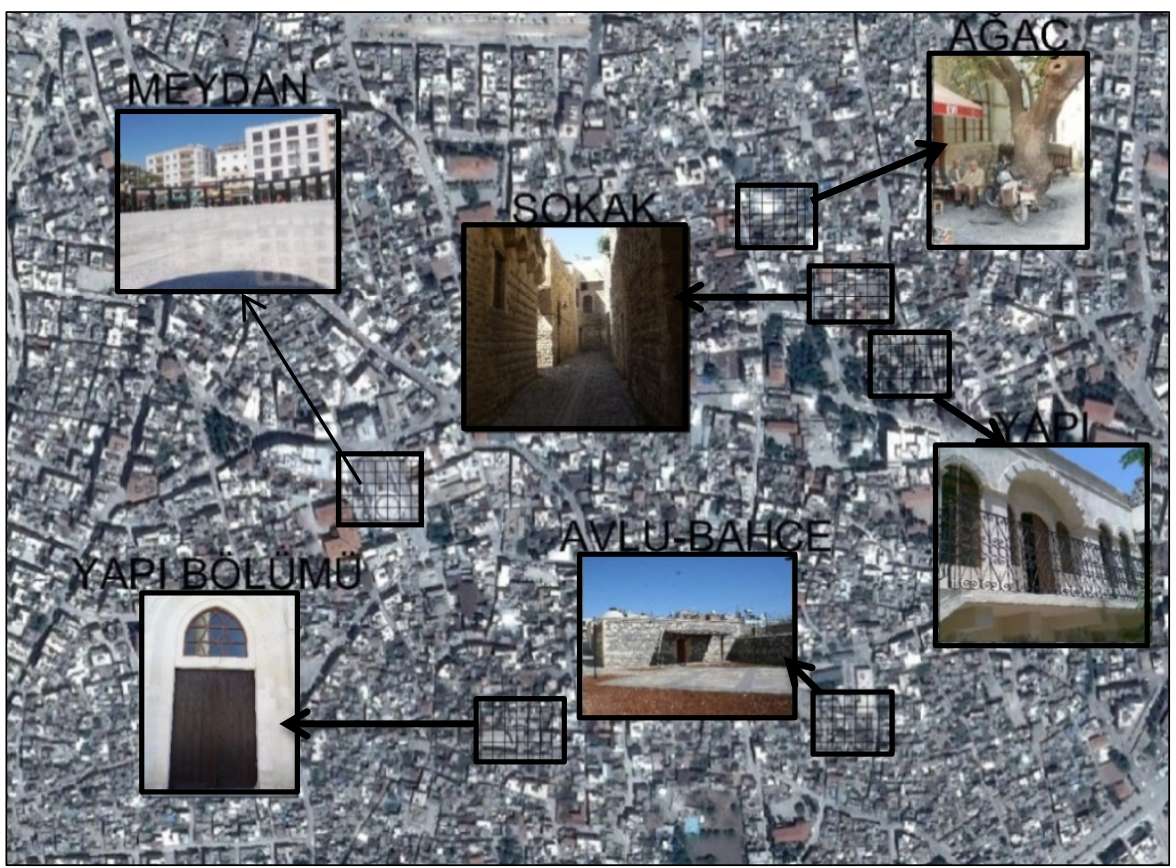

Şekil 2. Çalışma Alanında Kent Kimliği Öğeleri ve Konumları

\section{BULGULAR}

Anket çalışmasının ilk bölümünde katılımcılara yöneltilen sorularda \%59'unun erkek, \%41'inin bayan, \%68'inin bekar, \%32'sinin ise evli olduğu tespit edilmiştir. En yoğun katılım yaşı \%49 ile 18-25 yaş aralığı iken, en düşük katılım ise $\% 1$ oranı ile 55 ve üstü yaş aralığıdır. Eğitim düzeyi olarak incelendiğinde katılımcıların \%48'i Yüksekokul ve Fakülte mezunu iken, \%2'si İlkokul mezunu olduğu belirlenmiştir.

Çalışma kullanıcıların kentsel kimlik öğelerinin algısını fizyolojik süreç kapsamında biçim, renk, ölçü ve doku açısından ölçebilmek için Kilis Kentsel Sit alanında yapılmıştır. Bu doğrultuda ikinci bölümde 100 kullanıcıya sunulan 6 adet fotoğraftan 95 kişi Meydan öğesini doğru olarak tespit etmiştir. Bunu 56 kişi ile Ağaç, 51 kişi ile Avlu-Bahçe, 35 kişi ile Sokak ve 30 kişi ile Yapı öğesi takip etmiştir. En az algılanan öğe ise 15 kişinin doğru belirleyebildiği Yapı Bölümü olmuştur. Kullanıcılardan alınan cevaplar sonucunda elde edilen veriler \% olarak ifade edilmiştir (Çizelge 1 ). Kentsel kimlik öğelerinin her biri elde edilen algılanma oranları doğrultusunda oluşturulmuş olan daireler içerisine yerleştirilecek şekilde bir harita oluşturulmuştur (Şekil 3).

Kent kimlik öğelerinin kullanıcılar tarafından tespit edilmesini sağlayan belirleyici noktalar ve bu öğelere ait diğer özellikleri içeren bulgular ise, kullanıcılardan alınan cevaplar doğrultusunda ifade edilmiştir Meydan için 101, Yapı için 58, Avlu- Bahçe için 55, Sokak için 
50, Yapı Bölümü için toplam 22 farklı yanıt alınmıştır. (Çizelge 2, 3, 4, 5, 6 ve 7)(Şekil 4, 5, $6,7,8,9)$

Çizelge 1. Kentsel Kimlik Öğeleri Algı Oranları (\%)

\begin{tabular}{|l|c|}
\hline Kentsel Kimlik Öğeleri & Algılanma \\
\hline Meydan & 95 \\
\hline Ağaç & 56 \\
\hline Avlu- bahçe & 51 \\
\hline Sokak & 35 \\
\hline Yapı & 30 \\
\hline Yapı Bölümü & 15 \\
\hline
\end{tabular}

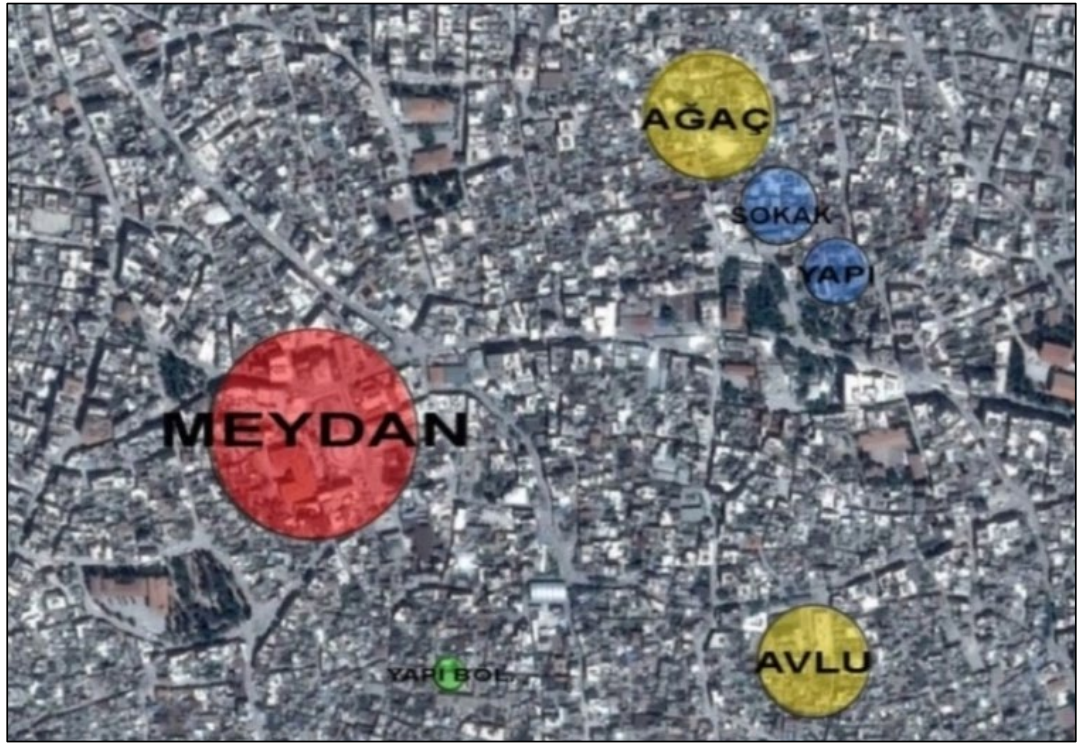

Şekil 3. Kentsel Kimlik Öğeleri Algı Haritası

Çizelge 2. Yapı Öğesinin Tespitinde Belirleyici Noktalar ve Diğer Özellikler (adet)

\begin{tabular}{|l|c|l|c|}
\hline YAPI & \multicolumn{1}{l|}{} \\
\hline Belirleyici noktalar & Ad. & Diğer özellikler & Ad. \\
\hline Taş iş̧iliği & 13 & Cafe olarak kullanım & 6 \\
\hline Giriş kemeri & 8 & Mağara & 4 \\
\hline Balkonu & 8 & Tarihi özelliği & 3 \\
\hline Demir parmaklıklar & 6 & Avlu & 3 \\
\hline Tarihi yapı & 4 & Su kuyusu & 2 \\
\hline Cafe olarak kullanım & 3 & Kahvesinin güzel olması & 2 \\
\hline Havuz & 3 & Odalar & 1 \\
\hline Kapı ve pencereleri & 3 & Farklı mimari & 1 \\
\hline Mimari yapı & 3 & Eğimli çatı & 1 \\
\hline Merdivenler & 2 & Bahçe & 1 \\
\hline Avlu & 2 & & $\mathbf{2 4}$ \\
\hline Döşseme & 1 & & \\
\hline Kuyu & 1 & & \\
\hline Mağara & 1 & & \\
\hline \multicolumn{1}{|l|}{ Toplam } & $\mathbf{5 8}$ & & \\
\hline
\end{tabular}




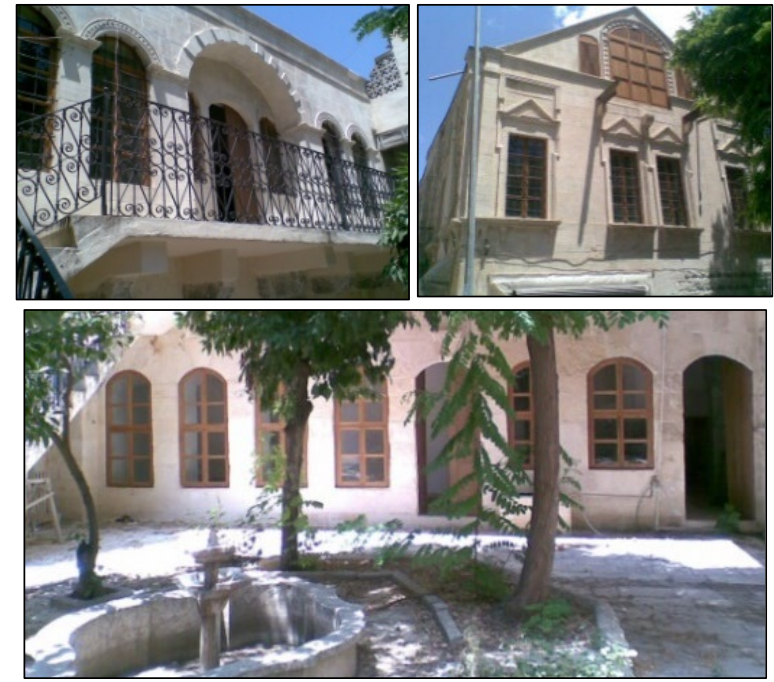

Şekil 4. Kilis Konağı

Çizelge 3. Yapı Bölümünün Tespitinde Belirleyici Noktalar ve Diğer Özellikler (adet)

\begin{tabular}{|l|l|l|r|}
\hline YAPI BÖLÜMÜ & Ad. & Diğer özellikler & Ad. \\
\hline Belirleyici noktalar & 7 & İbadethane & 1 \\
\hline Kapı & 6 & Minare & 1 \\
\hline Taş yapı & 2 & Kubbe & 1 \\
\hline Kullanılan malzeme & 1 & Ahşap işçilik & 1 \\
\hline Kapı üstündeki süsleme & 1 & Şadırvan & 1 \\
\hline Yeni restore edilmesi & 1 & Avlu girişi & 1 \\
\hline Mimari yapı & 1 & & Toplam \\
\hline Çok eski & 1 & & $\mathbf{6}$ \\
\hline SIk ziyaret & 1 & & \\
\hline Kenar sütunları & 1 & & \\
\hline Kapı genişliği Toplam & $\mathbf{2 2}$ & & \\
\hline \multicolumn{4}{|l|}{} \\
\hline
\end{tabular}
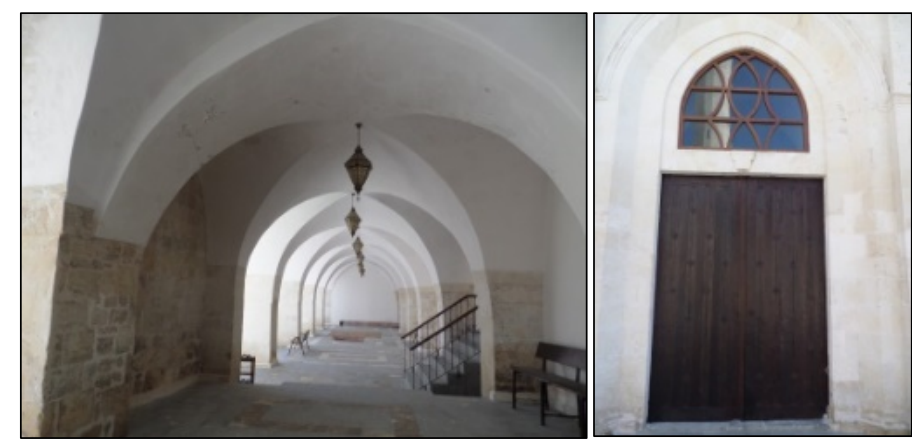

Şekil 5. Ulu Cami 
Çizelge 4. Avlu-Bahçe Tespitinde Belirleyici Noktalar ve Diğer Özellikler (adet)

\begin{tabular}{|c|c|c|c|}
\hline Belirleyici noktalar & Ad. & Diğer özellikler & Ad. \\
\hline Yapının kubbesi & 14 & Cafe olması & 5 \\
\hline Taş doku & 7 & 500 yıllık olması & 2 \\
\hline Tarihi yapı & 6 & Yapının kubbesi & 1 \\
\hline Duvarlar & 6 & Yeni restore edilmesi & 1 \\
\hline Avlu & 5 & Geniş bir yapı & 1 \\
\hline Yer döşemesi & 4 & Yüksek duvarlar & 1 \\
\hline Mekân güzelliği & 3 & Penceresiz olması & 1 \\
\hline Alan genişliği & 2 & Zemin & 1 \\
\hline Yapı tipi & 2 & Giriş kapısı & 1 \\
\hline Çevresi ile bütünlüğü & 2 & İniş merdiveni & 1 \\
\hline Yanındaki hamam & 2 & Toplam & 15 \\
\hline Kullanılan malzemeler & 2 & & \\
\hline Toplam & 55 & & \\
\hline
\end{tabular}
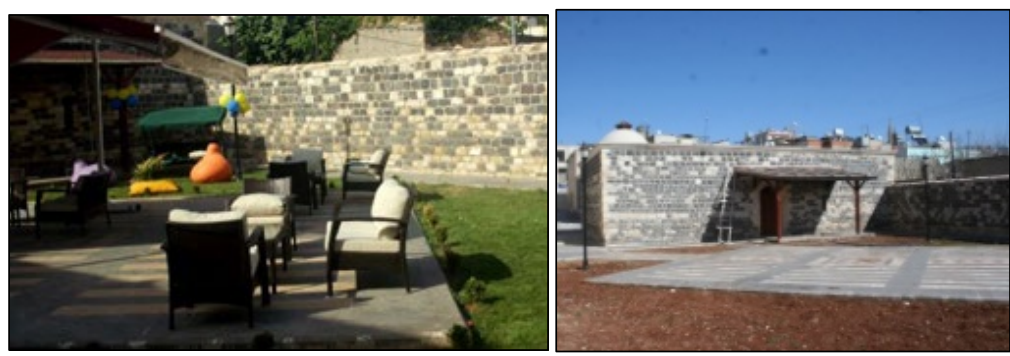

Şekil 6. Saklı Bahçe

Çizelge 5. Sokak Tespitinde Belirleyici Noktalar ve Diğer Özellikler (adet) SOKAK

\begin{tabular}{|l|c|l|c|}
\hline Belirleyici noktalar & Ad. & Diğer özellikler & Ad. \\
\hline Dar olması & 15 & Eski yapılar & 4 \\
\hline Taş yapı & 11 & Osmanlı mimarisi & 2 \\
\hline Eski taş evler & 6 & Çıkmaz sokakları & 1 \\
\hline Duvarlar & 4 & Dar sokakları & 1 \\
\hline Cumbalar & 3 & Yağmur olukları & 1 \\
\hline Tarihi yapı & 3 & Arnavut kaldırımı & 1 \\
\hline Pencere süslemeleri & 2 & $\begin{array}{l}\text { Restore edilen tek } \\
\text { sokak }\end{array}$ & 1 \\
\hline Mimari yapı & 1 & & $\mathbf{1 1}$ \\
\hline Görsel çekicilik & 1 & & \\
\hline Sokakların bütünlüğü & 1 & & \\
\hline Çocukluğun geçmesi & 1 & & \\
\hline Nostaljik görünüm & 1 & & \\
\hline Sokak üzerindeki konak & 1 & & \\
\hline \multicolumn{2}{|c|}{ Toplam } & $\mathbf{5 0}$ & \\
\hline
\end{tabular}



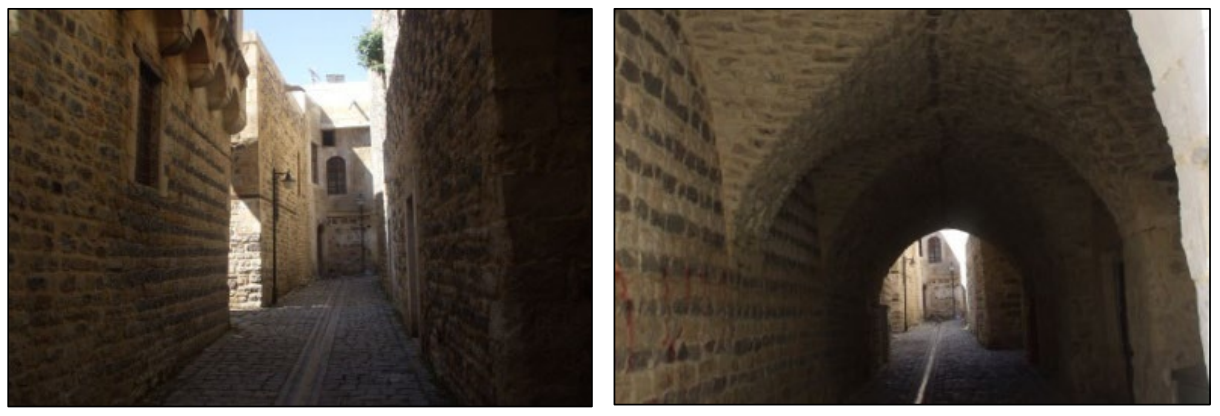

Şekil 7. Salih Efendi Sokağı

Çizelge 6. Ağaç Tespitinde Belirleyici Noktalar ve Diğer Özellikleri (adet)

\begin{tabular}{|c|c|c|c|}
\hline \multicolumn{4}{|l|}{ AĞACC } \\
\hline Belirleyici noktalar & Ad. & Diğer özellikler & Ad. \\
\hline Çay ocağı & 16 & Çayının güzel olması & 6 \\
\hline Yanındaki cami & 6 & Gölgesi & 3 \\
\hline Ağacın yaşı & 5 & Sosyalleşme mekânı & 3 \\
\hline Ağacın yapısı & 4 & Sokaktaki konumu & 1 \\
\hline Ağacın gövde kalınlığı & 3 & Yanındaki çay evi & 1 \\
\hline Yoğun kullanım & 2 & Yanındaki cami & 1 \\
\hline Yol kenarında olması & 2 & Toplam & 15 \\
\hline Çok eski olması & 2 & & \\
\hline Kaldırım & 1 & & \\
\hline Yanındaki sağlık ocağı & 1 & & \\
\hline Pencere yapısı & 1 & & \\
\hline Ağacın kovuğu & 1 & & \\
\hline Toplam & 44 & & \\
\hline
\end{tabular}
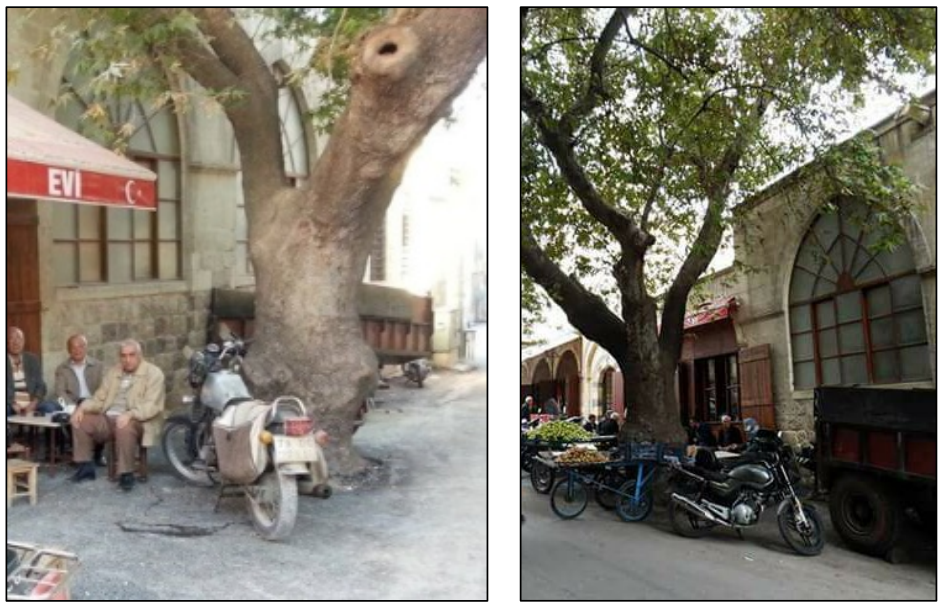

Şekil 8. Çınar Ağacı 
Çizelge 7. Meydanın Tespitinde Belirleyici Noktalar ve Diğer Özellikleri (adet)

\begin{tabular}{|c|c|c|c|}
\hline \multicolumn{4}{|l|}{ MEYDAN } \\
\hline Belirleyici noktalar & Ad. & Diğer özellikler & Ad. \\
\hline Binalar & 17 & Merkezi ve işlek & 10 \\
\hline Şehrin merkezi & 15 & Otopark & 6 \\
\hline Geniş bir boşluk & 10 & Etkinlik alanı & 5 \\
\hline Döşeme & 7 & Bayram yeri & 4 \\
\hline Düz olması & 6 & Bankalara yakınlığı & 4 \\
\hline Döşemenin çirkinliği & 5 & Korkunçluğu & 2 \\
\hline Geçiş alanı & 4 & Ulaşım kolaylığı & 2 \\
\hline SGK binası & 4 & Tek meydan & 2 \\
\hline Atatürk heykelli & 4 & Büyüklük & 2 \\
\hline Valilik önünde olması & 3 & Sürekli kullanılması & 2 \\
\hline Genişlik & 3 & Yeşil olmayışı & 2 \\
\hline Konum & 3 & Genişlik & 1 \\
\hline İş Bankası & 2 & Çirkinlik & 1 \\
\hline Estetikten uzak & 2 & Atatürk heykeli & 1 \\
\hline Lokantalar & 2 & Etrafındaki yapılar & 1 \\
\hline Mermer kaplama & 2 & Toplam & 45 \\
\hline Göz alışkanlığı & 1 & & \\
\hline Halk Bankası & 1 & & \\
\hline Herkese açık olması & 1 & & \\
\hline Yeni yapılan sokak & 1 & & \\
\hline Tek meydan olması & 1 & & \\
\hline Kullanılan malzeme & 1 & & \\
\hline Tasarım & 1 & & \\
\hline Mimari yapısı & 1 & & \\
\hline Kesilen ağaçların eksikliği & 1 & & \\
\hline Zarar gören tarihi doku & 1 & & \\
\hline Turkuaz restorand & 1 & & \\
\hline Işıklandırma & 1 & & \\
\hline Toplam & 101 & & \\
\hline
\end{tabular}

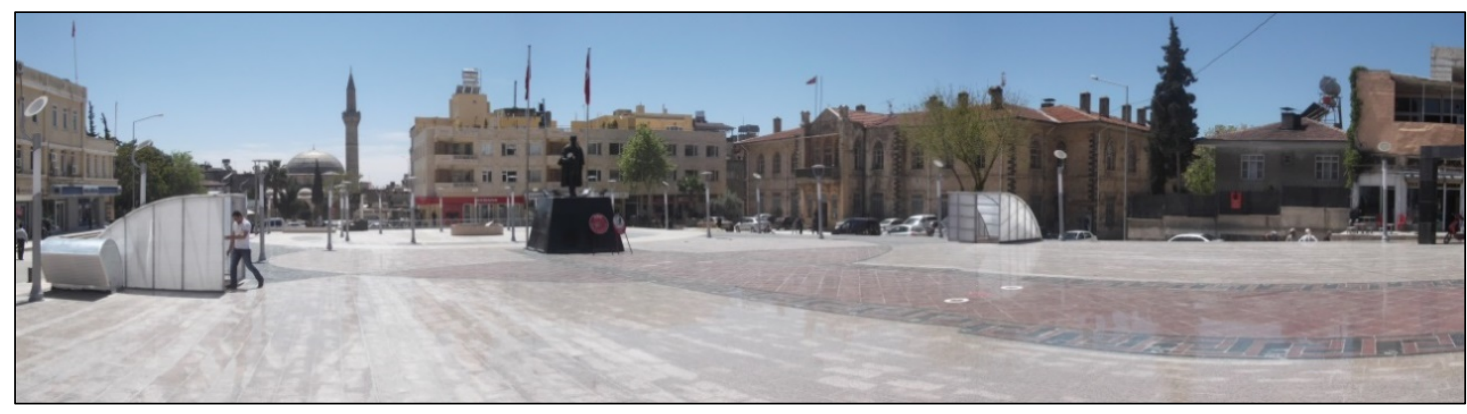

Şekil 9. Cumhuriyet Meydanı 
Anket çalışmasının sonraki aşamasında katılımcılardan kentin belirgin noktalarını ifade etmeleri istenmiştir. Bu doğrultuda bilişsel süreç içerisinde elde edilen bulgulara Çizelge 8'de yer verilmiştir. Buna göre en yüksek algı oranına sahip alan Cumhuriyet Meydanı iken onu Şeyh Muhammet Türbesi ve Ayşecik Parkı izlemiştir. Bu bağlamda sonuçları gösteren bir Kentsel Algı Haritası oluşturulmuştur (Şekil 10).

Çalışma alanında toplam 69 farklı belirgin öğe tespit edilmiştir. Bu öğeleri belirgin bulma sebeplerini de ifade eden kullanıcıların vermiş oldukları cevaplar düzenlenerek bir çizelge oluşturulmuştur (Çizelge 8).

Çizelge 8. Çalışma Alanında En Belirgin Ögeler ve Sebepleri Olarak Belirtilen Cevaplar (adet)

\begin{tabular}{|c|c|c|c|c|c|c|c|}
\hline \multicolumn{8}{|c|}{ Kentin En Belirgin Noktaları } \\
\hline $\begin{array}{l}\text { Cumhuriyet } \\
\text { Meydanı }\end{array}$ & 52 & Otogar & 4 & İzzet Usta & 1 & Kent ormanı & 1 \\
\hline $\begin{array}{l}\text { Şı Muhammet } \\
\text { Bedevi Türbesi }\end{array}$ & 37 & $\begin{array}{l}\text { Yeni Beşevler } \\
\text { Mahallesi }\end{array}$ & 4 & $\begin{array}{l}\text { Kemaliye } \\
\text { İlkokulu }\end{array}$ & 1 & $\begin{array}{l}24 \text { express } \\
\text { coffee }\end{array}$ & 1 \\
\hline Ayşecik Parkı & 22 & Polis Evi & 4 & $\begin{array}{l}\text { Emirgan Çay } \\
\text { Bahçesi }\end{array}$ & 1 & $\begin{array}{l}\text { Makaslı } \\
\text { Sokak }\end{array}$ & 1 \\
\hline $\begin{array}{l}\text { Söğütlüdere } \\
\text { Piknik Alanı }\end{array}$ & 15 & Akpınar & 4 & $\begin{array}{l}\text { Çınaraltı Çay } \\
\text { Evi }\end{array}$ & 1 & Asri mezarlık & 1 \\
\hline Üniversite & 14 & Ravanda Kalesi & 3 & Karababa & 1 & $\begin{array}{l}\text { Stadyum } \\
\text { büfe }\end{array}$ & 1 \\
\hline $\begin{array}{l}\text { Hacı Cümbüş } \\
\text { Cami }\end{array}$ & 10 & Dinazorlu Park & 3 & Hoca Camii & 1 & Hastane & 1 \\
\hline Kadı Cami & 9 & Kabaltı & 3 & Doğan Han & 1 & $\begin{array}{l}\text { Karataş } \\
\text { Parkı }\end{array}$ & 1 \\
\hline $\begin{array}{l}\text { Yaren Taş } \\
\text { Mekânlar }\end{array}$ & 8 & Akcurun Cami & 3 & Olea Otel & 1 & Romeos Cafe & 1 \\
\hline Murtaza Caddesi & 7 & $\begin{array}{l}\text { Salih Efendi } \\
\text { Sokak }\end{array}$ & 3 & Sabah pazarı & 1 & $\begin{array}{l}\text { Kalaycılar } \\
\text { Kervansarayı }\end{array}$ & 1 \\
\hline $\begin{array}{l}\text { Recep Tayyip } \\
\text { Erdoğan Meydanı }\end{array}$ & 7 & Oylum Höyük & 3 & $\begin{array}{l}\text { Ziraat } \\
\text { Bankası }\end{array}$ & 1 & $\begin{array}{l}\text { Toplam } \\
\text { cevap sayısı }\end{array}$ & 325 \\
\hline Eski Hamam & 6 & Canpolat Camii & 3 & Meşetlik & 1 & & \\
\hline Paşa Hamamı & 6 & $\begin{array}{l}\text { Şuhrabil Bin } \\
\text { Hasene Türbesi }\end{array}$ & 3 & $\begin{array}{l}\text { Kadı Cami } \\
\text { kavşağı }\end{array}$ & 1 & & \\
\hline $\begin{array}{l}\text { Şeyh Mahzur } \\
\text { Türbesi }\end{array}$ & 6 & Çatom Binası & 2 & Çevre Yolu & 1 & & \\
\hline $\begin{array}{l}\text { Kuyumcular } \\
\text { Çarşısı }\end{array}$ & 6 & İslambey Parkı & 2 & $\begin{array}{l}\text { Akıncl } \\
\text { Konağı }\end{array}$ & 1 & & \\
\hline $\begin{array}{l}\text { Adnan Menderes } \\
\text { Bulvarı }\end{array}$ & 6 & Toki & 2 & Mevlevihane & 1 & & \\
\hline $\begin{array}{l}\text { Odunpazarı } \\
\text { Caddesi }\end{array}$ & 6 & Kilis Konağı & 2 & $\begin{array}{l}\text { Resul Osman } \\
\text { Dağı }\end{array}$ & 1 & & \\
\hline Yeni Valilik Binası & 5 & Ulu Cami & 2 & $\begin{array}{l}\text { Öncüpınar } \\
\text { Kapısı }\end{array}$ & 1 & & \\
\hline Pasajlar & 5 & Gazi İlkokulu & 2 & Öğretmenevi & 1 & & \\
\hline Kilis Müzesi & 5 & İş Bankası & 2 & $\begin{array}{l}\text { Mercidabık } \\
\text { ovası }\end{array}$ & 1 & & \\
\hline Şehitler Parkı & 5 & Saklı bahçe & 1 & Merkez ptt & 1 & & \\
\hline
\end{tabular}


Çizelge 8. Çalışma Alanında En Belirgin Ögelerin Belirgin Olma Sebebi Olarak Belirtilen Cevaplar (adet)

\begin{tabular}{|c|c|c|c|c|c|c|c|}
\hline $\begin{array}{c}\text { Cumhuriyet } \\
\text { Meydanı }\end{array}$ & & $\begin{array}{c}\text { Şıh Muhammet } \\
\text { Türbesi }\end{array}$ & & Ayşecik Parkı & & Söğütlüdere & \\
\hline Şehrin merkezi & 22 & $\begin{array}{l}\text { Dini ve manevi } \\
\text { değeri }\end{array}$ & 16 & Sık kullanım & 4 & Piknik alanı & 7 \\
\hline Tek büyük meydan & 6 & Manzarası & 12 & Merkezi konum & 4 & Restorandı & 2 \\
\hline Ana ulaşım noktası & 6 & $\begin{array}{l}\text { Konumu, } \\
\text { yüksekte oluşu }\end{array}$ & 6 & Dinlenme alanı & 3 & $\begin{array}{l}\text { Tek mesire } \\
\text { alanı }\end{array}$ & 1 \\
\hline Büyük ve açık alan & 5 & $\begin{array}{l}\text { Her yerden } \\
\text { görünmesi }\end{array}$ & 6 & $\begin{array}{l}\text { Yıllardır var } \\
\text { olması }\end{array}$ & 2 & Kullanım sıklığı & 1 \\
\hline Tören alanı & 3 & $\begin{array}{l}\text { Gezinti amaçlı } \\
\text { kullanım }\end{array}$ & 3 & $\begin{array}{l}\text { Herkese açık } \\
\text { olması }\end{array}$ & 2 & Şehire yakınlığı & 1 \\
\hline Herkesce bilinmesi & 3 & $\begin{array}{l}\text { İbadet amaçlı } \\
\text { kullanım }\end{array}$ & 1 & $\begin{array}{l}\text { Alternatif } \\
\text { olmaması }\end{array}$ & 1 & Suyun varlığı & 1 \\
\hline Sık kullanım & 2 & & & Ferah olması & 1 & & \\
\hline Kalabalık oluşu & 2 & & & $\begin{array}{l}\text { Buluşma } \\
\text { noktası oluşu }\end{array}$ & 1 & & \\
\hline Görüntüsü & 1 & & & Eğlence alanı & 1 & & \\
\hline Atatürk heykeli & 1 & & & Anıların olması & 1 & & \\
\hline Çirkin görüntüsü & 1 & & & & & & \\
\hline Tarihi dokusu & 1 & & & & & & \\
\hline Yeni yapılması & 1 & & & & & & \\
\hline $\begin{array}{l}\text { Cumhuriyeti temsil } \\
\text { etmesi }\end{array}$ & 1 & & & & & & \\
\hline Üniversite & & $\begin{array}{c}\text { Hacı Cümbüş̧ } \\
\text { Camii }\end{array}$ & & Kadı Camii & & $\begin{array}{l}\text { Yaren Taş } \\
\text { Mekan }\end{array}$ & \\
\hline Öğrencisi olmak & 4 & Konumu & 3 & $\begin{array}{l}\text { Şehir } \\
\text { merkezinde }\end{array}$ & 8 & $\begin{array}{l}\text { Restorand } \\
\text { olması }\end{array}$ & 3 \\
\hline Kentte tek olması & 2 & $\begin{array}{l}\text { Şehrin girişinde } \\
\text { olması }\end{array}$ & 2 & Tarihi özellikleri & 3 & Otantik yapısı & 3 \\
\hline $\begin{array}{l}\text { Faaliyetleri ve } \\
\text { büyümesi }\end{array}$ & 2 & Büyük olması & 1 & $\begin{array}{l}\text { Cadde üzerinde } \\
\text { oluşu }\end{array}$ & 1 & Taş işçiliği & 2 \\
\hline İşyerine yakınlığı & 2 & Yokuşta olması & 1 & Taş işçiliği & 1 & Taş yapı olması & 1 \\
\hline $\begin{array}{l}\text { Tek modern yer } \\
\text { olması }\end{array}$ & 1 & Mimarisi & 1 & & & Tarihi özellikleri & 1 \\
\hline $\begin{array}{l}\text { Yakınında ikamet } \\
\text { edilmesi }\end{array}$ & 1 & Kolay ulaşım & 1 & & & & \\
\hline $\begin{array}{l}\text { Kentteki tek } \\
\text { hareketli yer }\end{array}$ & 1 & Çarşıya yakınlığı & 1 & & & & \\
\hline $\begin{array}{l}\text { Yeşil alanlardan } \\
\text { oluşması }\end{array}$ & 1 & & & & & & \\
\hline Kalabalık olması & 1 & & & & & & \\
\hline
\end{tabular}




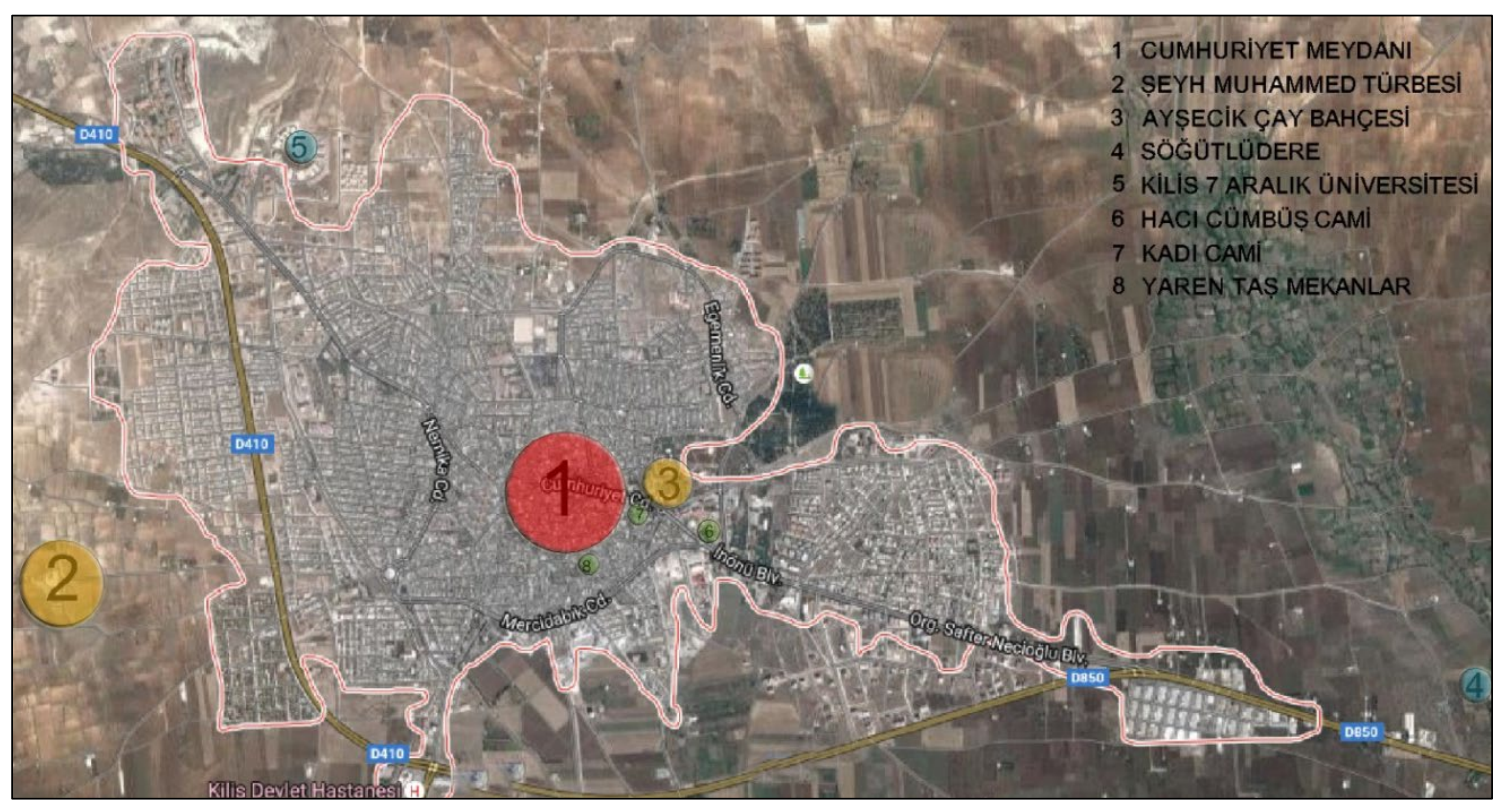

Şekil 10. Kentsel Algı Haritası

\section{TARTIŞMA VE SONUÇ}

Türksoy'un 1996 yılında Ankara'da yaptığı çalışma ile alt ve üst sosyal gruba ait iki ayrı kullanıcı grubu oluşturmuştur. Ardından kullanıcılardan zihinsel harita oluşturmalarını istemiştir. Sonuçlar göstermiştir ki yaşam biçimi ve koşullarının kenti algılamada önemli bir payı bulunmaktadır. Alt sosyal grubun fiziki çevreyi denetleme biçimi Bölgeler, Sınırlar, Odak Noktaları ve Bağlantı elemanları iken Üst sosyal grubunki ise Nirengi Noktaları olmuştur.

Türkoğlu 2002 yılında yaptığı çalışmasında İstanbul kentinin kullanıcılar açısından algılanmasını belirlemek amacıyla 5 temel imge elemanı üzerinden saptama yapmaya çalışmıştır. Nirengi Noktaları, Odak Noktaları, Bağlantı Elemanları, Sınırlar, Bölgeler olarak sınıflandırdığı imge elemanlarının yoğunluklarını ölçmüştür. Bulduğu sonuçlara göre en yüksek oran Taksim Meydanı en düşük oran ise Marmara Sahil yoluna aittir. Bu durum Nirengi Noktasının belirginliğini ortaya koymuştur. Bu açıdan bakıldığında çalışmanın sonucuyla uyumludur.

Aliağaoğlu'nun 2007 yılında, Balıkesir ile ilgili çalışmasında Lynch'in ilkelerinden yola çıkmış ve bunlar arasındaki algılanma ilişkilerini belirlemeye çalışmıştır. Çalışmanın sonucuna göre en çok algılanan Nirengi Noktaları olmuştur.

Konaklı ve arkadaşlarının 2010 yılında yaptıkları çalışma ile Adana 5 Ocak ve Uğur Mumcu meydanlarının mekânsal algılanması ve davranışsal başarımını tespit etmeye çalışmışlardır. Çalışma sonucunda meydanların mevcut durumları ile birlikte 2 farklı öneri de değerlendirilmeye sunulmuştur. Çalışma mekân ile insan arasındaki ilişkinin algı aracılığıyla kurulduğunu ifade etmiş, mekânı algılamayı sağlayan estetik öğeleri içinde bulunduran fiziksel özelliklerin önemini belirtmiştir.

Tüm bu sonuçlar irdelendiğinde kentler artan nüfusun etkisiyle farklı taleplerin artışını da beraberinde getirmektedir. Bu taleplere cevap verme isteğiyle yapılan uygulamalar ile birlikte yetersiz koruma uygulamaları Tarihi Kent merkezlerinin belirli alanlar içerisine sıkışmasına ve daha az algılanabilir olmasına sebep olmaktadır. Oysa ki kuruluşundan itibaren günümüze kadar geçen süreç içerisinde, pek çok tarihi ve kültürel deneyimin sonucunda oluşan Kentsel kimlik öğeleri, kentin şekillenmesinde baş aktör olarak kabul edilmelidir.

Bu bağlamda yapılan kullanıcıya yönelik araştırmada anket yöntemiyle, Kentsel kimlik öğeleri başlığı altında değerlendirilen mekânlar algılanma oranlarına göre değerlendirildiğinde aşağıdaki sonuçlar elde edilmiştir:

- Meydan en üst düzeyde algılanan mekân olmuştur. Bu durumun yoğun kullanım ve merkezi konumundan kaynaklı olduğu düşünülmüş, nitekim cevaplardan da bu düşüncenin doğru olduğu tespit edilmiştir. 
- Orta derecede algılanan ağaç ve avlu-bahçe öğelerinin bulunduğu mekânların işletme olarak faaliyet göstermesinin, kullanıcılar tarafından rahatça algılanmasına ve tanınmasına katkıda bulunduğu belirlenmiştir.

- Sokak ve yapı öğelerinin kullanıcılar üzerinde düşük bir etki yarattığı, ancak konumundan ve kullanımından kaynaklı olarak belirgin algılandığı gözlenmiştir.

- Yapı bölümü öğesinin en düşük algılanma oranına sahip olmasının nedeni olarak ise kentte çok işlek olmayan bir konumda yer alması ve mahalle arasında sıkışmış olmasından kaynaklandığı düşünülmektedir. Tarihi öneme sahip olan yapı pek çok kullanıc tarafından tespit edilememiştir.

Kentin belirgin noktalarının tespit edilmesine yönelik sorulan açık uçlu sorularda ise:

- Cumhuriyet Meydanı ilk sırada yer almıştır. Bu durumun Kentin ana ulaşım noktası olmasından kaynaklı olduğu tahmin edilmektedir. Kentin en sık kullanılan ve kente hakim bir tepe üzerinde yer alan Şeyh Muhammet Türbesinin dini amaçlı bir alan olmasının yanında sosyal bir alan olarak da kullanılmasının algılanma oranı üzerinde etkisinin olduğunu cevaplar da destekler niteliktedir. Ayşecik Çay Bahçesi, Söğütlüdere Piknik Alanı ve Kilis 7 Aralık Üniversitesi de sırasıyla belirgin olan diğer noktalar olarak belirlenmiştir.

Bütün bunlardan yola çıkarak, kullanım sıklığına bağlı olarak kullanıcıların mekânlar üzerindeki algılarının paralel olduğunu, kentin sıkışık düzeninden kaynaklı pek çok kişinin aslen bu kent nüfusuna kayıtlı olmasına rağmen, tarihi öneme sahip çok sayıdaki Kent Öğelerini farkında olmadığı görülmüştür. Aynı zamanda kullanıcılar tarafından mekânlara ait tarif ve tanımlamalar yapılırken çoğunlukla, kente ait belirgin noktaları ve Kent Kimlik Öğelerini değil de, günlük yaşamın en merkezi noktalarında bulunan ve kullanım sıklığından kaynaklı olduğunu düşünmemize sebep olan Fırın, Kasap, Tatlı Dükkanı gibi mekânların tercih edildiği belirlenmiştir.

Bu bağlamda geçmişle aramızda bağ kuran, belli birikim ve deneyimlere sahip kentin gelecek kuşaklara sağlıklı bir şekilde aktarılabilmesi için, korumacı bir tutum içerisinde yaklaşılması oldukça önemlidir. Kent formunun ana bileşenleri olan Kent Kimlik Öğelerinin ön plana çıkarılarak kent içerisindeki rollerinin sağlamlaştırılması ve kentin kullanıcılar tarafından daha rahat bir şekilde algılanmasına katkı sunması gereklidir. Bu durum yapılacak olan çalışmalarda toplumun bilinçlendirilmesi, kentleşme baskısının yarattığı olumsuz durumların ortadan kaldırılması ve doğru düzenleme çalışmalarıyla sağlanabilir.

\section{KAYNAKLAR}

Aliağaoğlu, A., 2007. Davranışsal Coğrafyaya Bir Örnek: Öğrenci Merkezli Balıkesir Şehir İmajı. Fırat Üniversitesi, Sosyal Bilimler Dergisi, 17(1), 17-44.

Çakçı, I., ve Çelem, H.,2009. Kent Parklarında Görsel Peyzaj Algısının Değerlendirilmesi. Ankara Üniversitesi Ziraat Fakültesi, Tarım Bilimleri Dergisi, 15(1), 88-95.

Gür, Öymen, Ş.,1996. Mekân Örgütlenmesi. Gür Yayıncılık, Trabzon,s.257.

Konaklı N., Altunkasa, M.F., Uslu, C., ve Sirel, B.,2010. Mekânsal Algılama ve Mekânın Davranışsal Başarımı: Adana 5 Ocak ve Uğur Mumcu Meydanı Örneği. Peyzaj Mimarlığı 4. Kongresi, pp. 283-295,(In Turkish).

Lynch, K., 1960 . The İmage of the City. The Mit Press, Cambrıdge, Massachusetts.

Lynch, K.,2010. Kent İmgesi. Türkiye İş Bankası Kültür Yayınları,İstanbul.

Nasar, J.L.,1990. The Evaluative Image of the City, Journal of the American Planning Association, (56), 41-53.

Önem, B.A., ve Kılınçaslan, İ., 2005. Haliç Bölgesinde Çevre Algılama ve Kentsel Kimlik. İTÜ Mimarlık, Planlama, Tasarım Dergisi. 4(1), 115-125.

Özak Öymen, N. ve Gökmen Pulat, G., 2009. Bellek ve Mekân İlişkisi Üzerine Bir Model Önerisi. İTÜ Mimarlık, Planlama, Tasarım Dergisi. 8(2), 145-155.

Steinitz,C.,1968. Meaning and the Congruence of Urban Form and Activity. Journal of the American Planning Association, (34)4, 233-247.

Turgay, O., 2013. Mekânların "Arayüz" Nitelikleri Bağlamında Gündelik Yaşantıdaki Kalıcılığı. Beykent Unıversıty Journal Of Scıence and Engıneerıng, 6 (1), 27-46. 
Türkoğlu, D,H., 2002. Kentsel İmge: İstanbul'dan Bulgular. İstanbul Teknik Üniversitesi, Mimarlık, Planlama, Tasarım Dergisi, 1(1), 57-64.

Türksoy, Ö.,1996. Çevresel Psikoloji, Kentsel Planlama ve Kentsel Bütünleşme, 86 (1), 1317.

\section{EXTENDED ABSTRACT}

Perception is defined as the process of selecting, organizing, and interpreting information received through senses (Porteous, 1996; Bell, 1999, Çakçı and Çelem, 2009). This definition was handled together with informatics by Downs and Stea (1973) (from Özak and Gökmen, 2009), working on environmental psychology. It is explained as the coding, storing, remembering and decoding process of the information received from the spatial domain. From this point of view, the notion of perception is related to the process of conversion of the stimuli taken in close proximity through the senses into wisdom, in other words "cognition." The process of perception is realized by stored information, acquired knowledge and sensible physical data. For a perceived situation and space to be sensible for the person, environmental factors such as the past experiences, education, cultural items, light, sound, smell and texture, or any internal reason can be effective (Turgay, 2013). In other words, perception is the environmental warning and information processing concept. The concept of space reflects human existence beyond being a sum of perceptions and thoughts. Space is the most principal element which is built by humans, which constitutes the basis of an environment, which is not defined by definite boundaries, and which evolves based on past experiences. There is no doubt that the environmental shape has played a tremendous role in creating the image. The similarities in the definition process and even showing surprise at same points indicate that the knowledge gained is based on familiarity with the place in question. This relationship between the image and the physical form constitutes our spatial perception (Lynch, 1960). The concept of spatial perception is a process that starts with the sense (the first image) and extends to sense-making (the general image) and the meaning (the real image). The functioning of short and long-term memory structures is important in understanding the space and in the formation of image belonging to that space. The images and inputs of the individual acquired through their past experiences are stored in long term memory. In newly encountered places, the space is perceived by using processes such as association, matching and comparison, and the imagination belonging to this space is created. Since it stores more conceptual thoughts in the long-term memory, it is possible to perceive the space as a meaningful whole (Turgay, 2013).

This study aims to measure and evaluate spatial perception based on user research. The study that examines the relationship between space and perception has been framed on the premise that the individual first identifies the defining points of space and then determines the space correctly.

It is possible to express the phases of the work as follows; 1) Determination of urban identity Items and places in the field: 6 separate groups such as the courtyard, the building, the building department, the street, the square and the tree were formed. One sampling area for each group was selected and presented to the user. 2) Formation and implementation of user research form: User research consists of two parts. In the first part, there are questions about user profile such as age, gender, occupation, educational status. in the second part, definitions belonging to the places are included. In the first phase of space evaluation, they were asked to identify each location and state the decisive points that enabled them to make that choice through the Urban Identity Items. At the next stage, participants were asked to write the most obvious points in the city. This way, they tried to express their positions based on their perceptions and to ensure their order. To indicate why they found those places significant, a specific place was reserved to discuss the reasons for the answers. User survey forms containing photographs of designated locations were applied on randomly selected 100 subjects and we paid careful attention to the fact that the participants were residing in the city for at least 3 years. 3) Statistical analysis of survey data: The results of the user survey were evaluated statistically, and relative findings were obtained. 4) Creation of visual maps in the direction of discovery: Determination ratios of urban identity items, determination of defining points, identification of the significant points of the city, and maps were created in this direction. 
At the end of the study that was conducted to identify the user perceptions of Urban Identity within Kilis Urban Site, it was detected that the most perceived place was Square with 95\%, followed by Tree with 56\%, Courtyard-garden with $51 \%$, Street with $35 \%$ and Buildings with $95 \%$. The least perceived places were Building Parts with $15 \%$. In the next step, according to the data obtained to determine the defining places of the city, Cumhuriyet Square had the highest perception rate followed by Şeyh Muhammet Türbesi and Ayşecik Park. A total of 69 defining distinct elements were identified in the study area. When the user survey conducted in this context was evaluated according to the perception rates of the spaces under the title of Urban Identity Items, the following results were obtained: The square was the most perceived place. It was thought that this situation originated from its intensive use and central position, and this thought was affirmed from the answers. It has been thought that the places where the trees and courtyard-garden items that are perceived at medium level are also used as business enterprises, which helps its being easily recognized and perceived by the users. It has been observed that the street and building elements have a low effect on the users, but they are perceived as defining due to their location and usage. It is thought that since the building elements are located in a very inactive part of the city and are stuck between the neighborhoods, they have the lowest perception rates. In open-ended questions asked to determine the specific points of the city, Cumhuriyet Square took the first place. It is estimated that this situation is due to its position as the main transportation point in the city. City's most commonly used place Şeyh Muhammet Türbesi, located on a hill overlooking the city is used as a social space as well as a religious site; that supports its impact on its perception rate. Ayşecik Çay Bahçesi, Söğütlüdere Picnic Area and Kilis 7 Aralık University were also identified as other significant points respectively. Based on all these facts, it has been seen that the perceptions of users are parallel to the frequency of use; and that many people were not aware of many historical Urban Items due to city's congested formation though they were originally registered residents of the city. 